\title{
Nuclear cogeneration with high temperature reactors
}

\author{
Grzegorz Wrochna ${ }^{1, *}$, Michael Fütterer ${ }^{2}$, and Dominique Hittner ${ }^{3}$ \\ ${ }^{1}$ National Centre for Nuclear Research NCBJ, Pasteura 7, 02-093 Warsaw, Poland \\ 2 Directorate for Nuclear Safety and Security, JRC, PO Box 2, 1755ZG Petten, The Netherlands \\ ${ }^{3}$ LGI Consulting, 6, cité de l'Ameublement, 75011 Paris, France
}

Received: 5 April 2019 / Accepted: 4 June 2019

\begin{abstract}
Clean energy production is a challenge, which was so far addressed mainly in the electric power sector. More energy is needed in the form of heat for both district heating and industry. Nuclear power is the only technology fulfilling all 3 sustainability dimensions, namely economy, security of supply and environment. In this context, the European Nuclear Cogeneration Industrial Initiative (NC2I) has launched the projects NC2I-R and GEMINI+ aiming to prepare the deployment of High Temperature Gas-cooled Reactors (HTGR) for this purpose.
\end{abstract}

\section{Clean energy needs beyond electricity}

\subsection{Current and future energy production}

Clean energy production is a high European priority and it is widely recognized as a growing need in the world. So far, most of the effort was concentrated on electric power because the solution is rather straightforward. Electricity, however, accounts for $18 \%$ of the total energy consumption only (Fig. 1). Other applications, namely heat and transport, are today based almost $100 \%$ on fossil fuel with high emissions, mainly natural gas, oil and coal.

In Europe, electricity represents $24 \%$ of the energy consumption, while heating and cooling for residential and industrial uses accounts for $50 \%$ [2]. Almost $100 \%$ of derived heat is obtained from combustion. This implies that an effective European energy policy has to address this sector with high priority, although it is merely invisible to the general public. The expected political and socioeconomic benefit is very significant.

So called "renewable energy sources" cannot provide sufficient solution for heat production. Wind turbines and solar panels produce electricity and using it to generate heat would be a waste of energy and would be very expensive, especially for industrial purposes. The only exceptions are solar thermal power stations, focusing solar radiation by mirrors, but they can be effectively used only in regions with high insolation and a high fraction of direct (as opposed to diffuse) sunlight.

The only option able to address all three virtues of the "sustainability triangle", namely economy, security of supply and environment, is nuclear energy. It is widely

\footnotetext{
* e-mail: grzegorz.wrochna@ncbj.gov.pl
}

used today for electricity production. In Europe, industrial nuclear power plants produce currently $26 \%$ of all electricity and $52 \%$ of electric energy from non-combustible sources. However, out of all industrial and district heat only $0.2 \%$ comes from nuclear reactors.

\subsection{High temperature industrial heat}

About $95 \%$ of the process heat market in most industrialized countries is characterized by high energy intensity and high temperature (Fig. 2). This fact, coupled with the strong dominance of fossil fuels in heat production, results in high emissions, not only of $\mathrm{CO}_{2}$, but also of fine dust, heavy metals, $\mathrm{NO}_{x}, \mathrm{SO}_{3}$ and others. Consequently, many issues concerning public health, environment, energy security, geopolitics, socio-economics etc. are at stake. As long as no commercially viable alternative exists, fossil fuels remain the sole option for the many high temperature processes that power our industry.

In Europe, about $89 \mathrm{GW}_{\text {th }}$, i.e. $50 \%$ of the process heat market is found in the temperature range up to $550^{\circ} \mathrm{C}$ (today mainly in the chemical industry, in the future possibly in steelmaking, hydrogen production, etc.) [3,4]. Therefore, to advance broader applications of nuclear cogeneration in the industrial processes that require heat supply at high temperature, international technology developments are focusing on nuclear reactor types designed to deliver this high temperature heat.

Various reactor concepts can be considered, e.g. the well-known Generation IV International Forum concepts, including modular High Temperature Reactors (HTR) and their long-term evolution towards very high temperatures (VHTR), Super-Critical Water Reactors (SCWR), Molten Salt Reactors (MSR) and different Fast neutron Reactor 


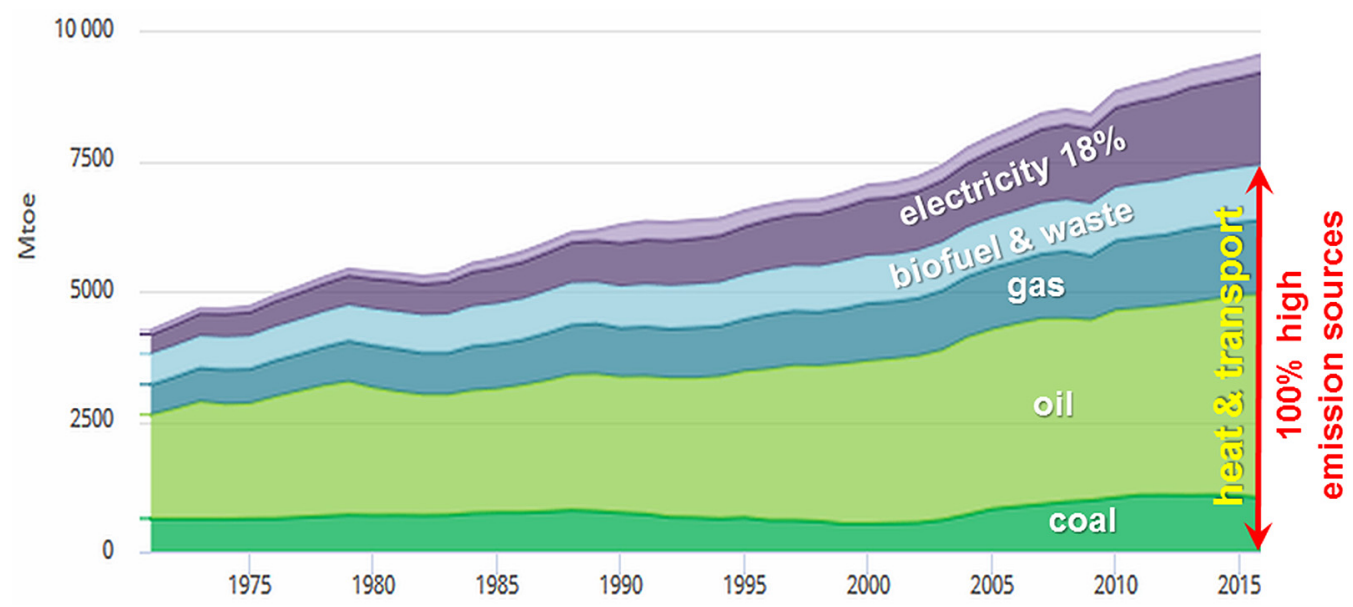

Fig. 1. World energy consumption by source (Adapted from [1]).

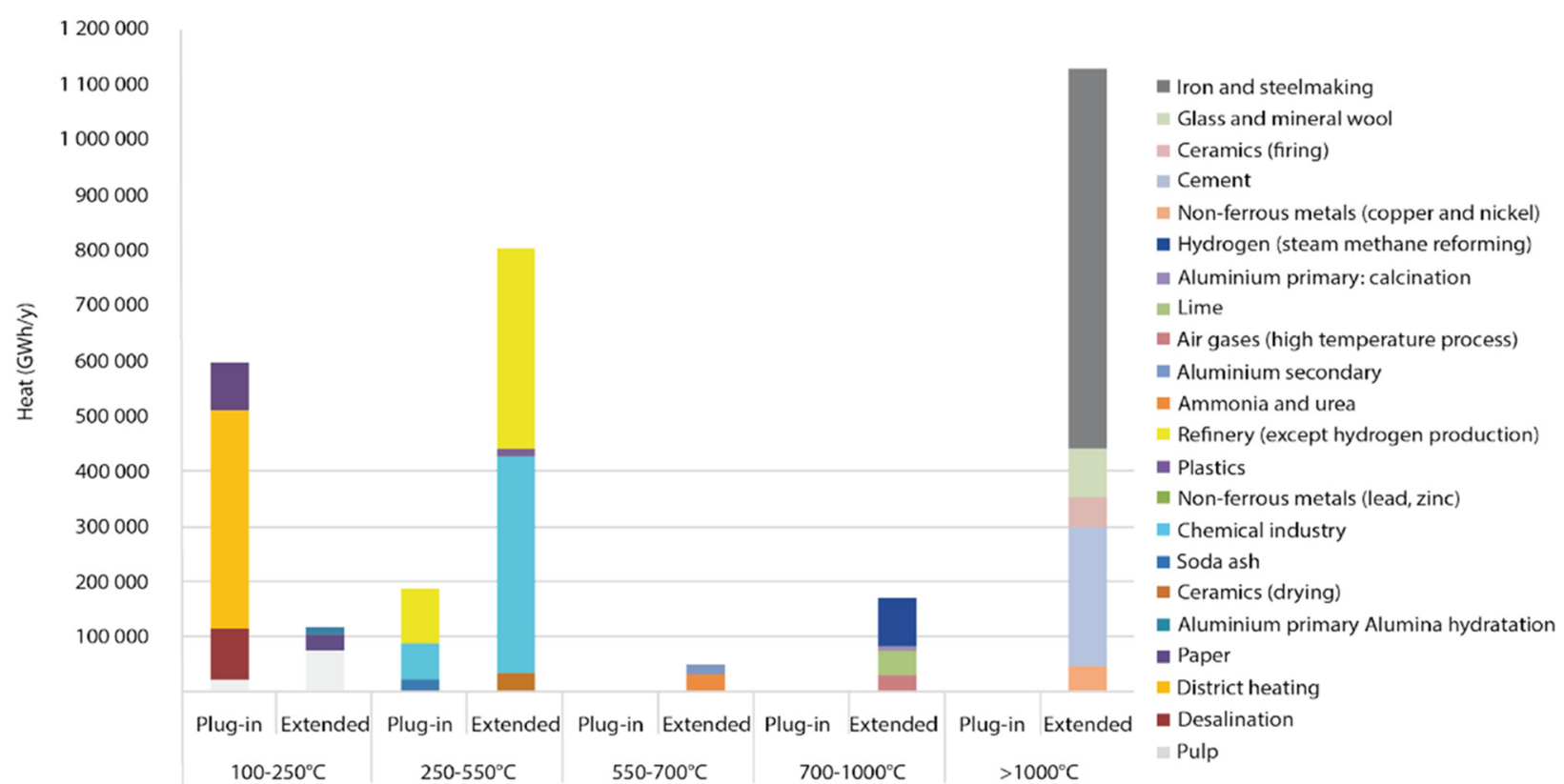

Fig. 2. Distribution of the heat market by temperature class and sector [3].

concepts cooled by either Sodium (SFR), Lead (LFR) or Gas (GFR). However, for near-term solutions delivering process steam up to $550^{\circ} \mathrm{C}$, the HTR is currently the only option [5] and the only one that covers the largest range of temperature. Moreover, modular HTR designs feature unique simplicity owing to their intrinsic passive safety concept which makes expensive redundant and active engineered safety systems superfluous. This is a clear advantage for siting in proximity to industrial end users and for competitiveness, which are prerequisites for any industrial deployment.

\subsection{Nuclear cogeneration industrial initiative}

The challenges described above are in the focus of the European Nuclear Cogeneration Industrial Initiative
(NC2I) [6]. The organisation has been created as one of three pillars of the Sustainable Nuclear Energy Technology Platform (SNETP) [7]. In line with the objectives and timing foreseen by the Strategic Energy Technology Plan (SET-Plan) issued by the European Commission, NC2I proposes an effective nuclear technology for reaching the SET Plan targets. Its mission stems from the assessment of energy needs of European economy and is focusing on realizing its mission: "Contribute to clean and competitive energy beyond electricity by facilitating deployment of nuclear cogeneration plants".

NC2I thus strives to provide a non-electricity nuclear contribution to the de-carbonisation of industrial energy, which is required, as mentioned before, mainly as high temperature process heat. Considering the relatively shortterm deployment objectives, among the different nuclear 


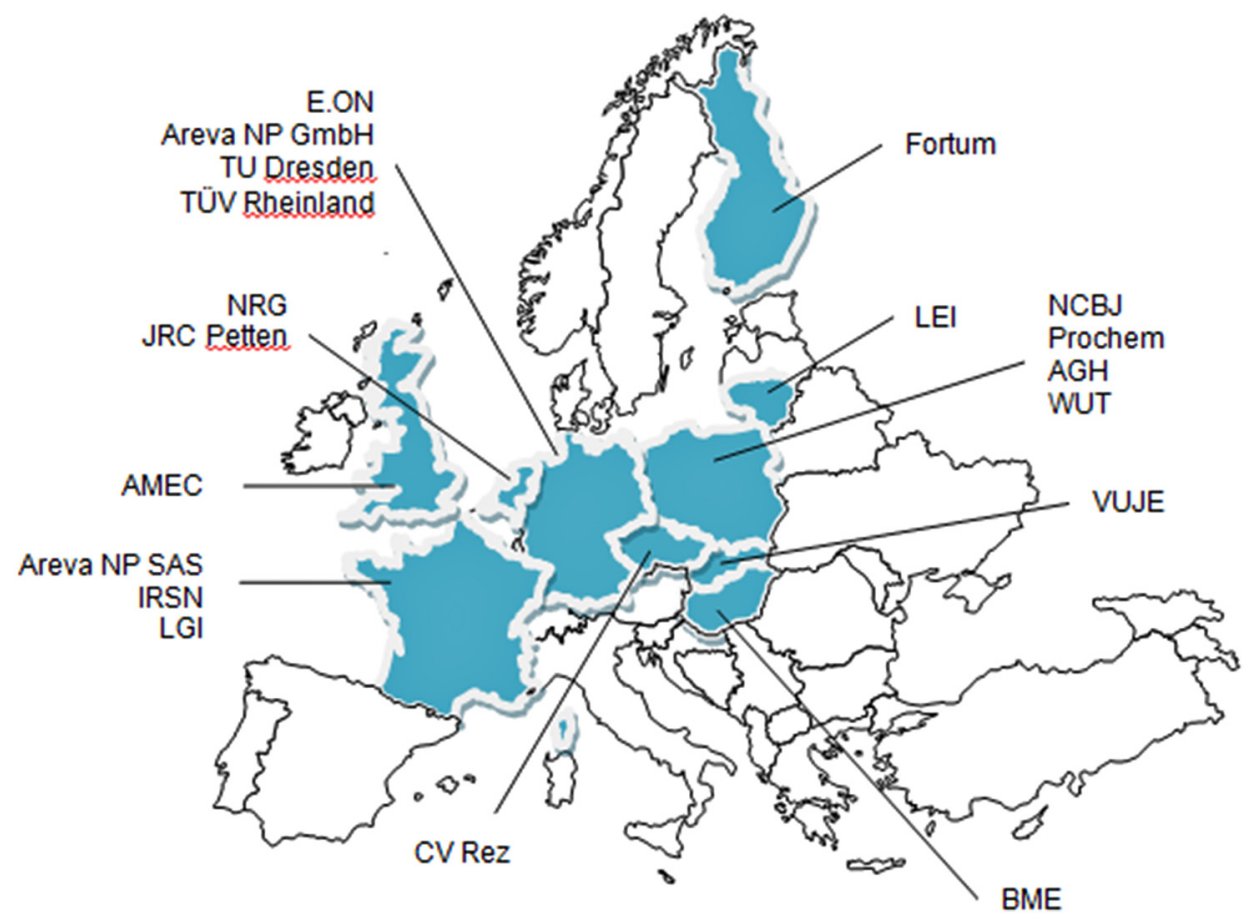

Fig. 3. NC2I-R partners. NorthWest University from South Africa also participated.

technologies that can be used to operate reactors at higher temperatures than present LWRs, NC2I gives highest priority to HTGR, because:

- It is the most mature technology (750 reactor-years operational experience), capable to be deployed before 2050.

- It can fully address, without further development, the needs of a large class of processes receiving heat or steam as a reactant from steam networks (typically around $550^{\circ} \mathrm{C}$ ); these are mainly the processes of chemical and petrochemical industries. Plugging into existing infrastructure of steam networks, HTGR plants could substitute present fossil fuel fired boilers and cogeneration plants which may then serve as back-ups for the case of outages.

- It has the potential for addressing in the longer-term other types of applications presently not connected to steam networks, in particular bulk hydrogen production and other applications at temperatures higher than $550{ }^{\circ} \mathrm{C}$.

NC2I proposes, therefore, as a first step, a deployment of HTGR systems of these "plug-in" applications on existing steam networks.

Although, HTGR technology is mature for such applications, the economic competitiveness of nuclear steam production, as well as its flexibility and reliability to adapt to industrial needs is yet to be demonstrated. Moreover, even if modern modular HTGR technology, which offers a very high safety level, has already been licensed (HTTR in Japan, HTR-10 and HTR-PM in China, not to speak of the preliminary safety reviews of MHTGR in the US and the HTR-Modul in Germany), a nuclear reactor has not been licensed yet for coupling with high temperature industrial processes. Any large deployment of
HTGR for industrial process heat supply calls for prior demonstration at industrial scale of such a coupled system. $\mathrm{NC} 2 \mathrm{I}$ is paving the way to this demonstration in Europe.

In order to realise this goal, $\mathrm{NC} 2 \mathrm{I}$ has launched two $\mathrm{EU}$ projects "NC2I-R" and "GEMINI+". These projects are cofinanced by the Euratom FP7 and Horizon 2020 Framework Programs, respectively.

\section{The project NC2I-R}

\subsection{Overview}

The NC2I-R project was run from 2013 to 2015 by a consortium of 20 partners (Fig. 3). Building on an earlier project called EUROPAIRS [8], NC2I-R has drawn an inventory of all infrastructures and competences considered crucial for the establishment of new nuclear cogeneration, both at the scale of demonstration and of industrial deployment. This stock-taking spanned in particular the EU, but also reached out to selected countries overseas where use of nuclear cogeneration was/is industrial practice or planned for the future.

A second large activity investigated the requirements regarding the licensing process, safety demonstration and R\&D needs of a nuclear co-generation system. Technology state-of-the-art and previous experience gained from licensing of existing and past nuclear cogeneration facilities in Europe and overseas were gathered and reviewed which led to a roadmap for licensing a new installation in Europe.

Demonstration and deployment options for nuclear cogeneration were identified and modeled to evaluate and rank them according to industrial and/or policy-driven interests. More detailed economics analyses were performed including sensitivity studies. These included factors 
influencing the economics \& financing, and conditions of economic viability. General specifications for a demonstrator program including siting were defined, and the most promising chemical industry sites in Europe were mapped.

\subsection{Feedback from past and planned nuclear cogeneration installations}

A total of 36 projects could be identified and contact persons be found using the international network of the NC2I-R consortium. From those, 23 from 10 countries have provided feedback on a variety of applications. The most common were:

- district heating (HU, CH, CZ, SK, S, ROC, FIN, RU);

- seawater desalination (KZ, JA);

- process steam for paper and pulp $(\mathrm{N}, \mathrm{CH})$;

- salt refining (D);

- process steam for reforming of gas and coal (D);

- (petro-)chemical (D, CAN);

- nuclear processes (UK, CAN).

Five main reasons were found to trigger plans for nuclear cogeneration installations:

- security of supply;

- conducting R\&D on industrial nuclear cogeneration;

- reducing carbon and other emissions;

- economic benefit;

- increasing the efficiency of an existing NPP.

While each nuclear cogeneration project is different, the following stakeholders, or at least some of them were involved from the beginning of the project:

- manufacturer of the plant;

- operator;

- utility;

- end-user (industry, municipality);

- plant owner;

- political representatives at different levels.

Concerning technical aspects, in most of the projects, the cogeneration installation was included in the original design and did not require a revamp/upgrade of the NPP. The great majority of the commissioned projects did not encounter unexpected difficulties. However, the NPP Agesta in Sweden had to face problems related to the FOAK character of the heat source. Paks in Hungary had technical problems related to the conventional heat transport system. All projects require back-up power to cover O\&M outages. Fossil fuel boilers are used for backup, and the back-up capacity is minimized by planning outages during summer when no domestic heating is required.

Reliable financial information on the nuclear projects was very difficult to obtain. The CAPEX ranges from a few dozens of million $€$ for a capacity of several $100 \mathrm{MW}$ to more than 1000 million $€$ for the Loviisa 3 project, using a reactor with a planned electric capacity between $1200 \mathrm{MW}_{\mathrm{e}}$ and $1700 \mathrm{MW}_{\mathrm{e}}$ and a thermal capacity between $2800 \mathrm{MW}_{\text {th }}$ and $4600 \mathrm{MW}_{\mathrm{th}}$.

The investment was either made by the government (Halden in Norway, Paks in Hungary), or absorbed within a utility budget - most of the time owned partly by the government - (Slovenske Elektrarne for Bohunice in Slovakia, Refuna AG for Beznau in Switzerland; Refuna is an 80-20 public-private partnership).

The levelized cost of energy (LCOE) was also difficult to obtain. The Loviisa 3 project in Finland, estimated that the energy produced by the NPP would have been $7 € / \mathrm{MWh}$ cheaper than in a biofuel-fired scenario, and $18-26 € / \mathrm{MWh}$ cheaper than in a scenario where the primary fuel was coal, a statement which obviously depends on the cost assumptions made for biofuel and coal. For Paks in Hungary, the initial levelized cost of delivered electricity was (11 HUF1985/kWh) in 1985, at today's exchange rate equivalent to $0.0358 €_{2013} / \mathrm{kWh}$, a little useful value 30 years later. The initial levelized cost of delivered heat was $2.9 € /$ GJ (894 HUF/GJ).

\subsection{Safety and licensing}

Safety oriented work in NC2I-R aimed at providing input to both designers and regulators about the licensing, safety requirements and $\mathrm{R} \& \mathrm{D}$ needed to establish the safety demonstration of a nuclear co-generation system. The experience gained through the licensing of existing and past nuclear facilities with co-generation capabilities was collected and reviewed. Based on this feedback and taking into account recent trends for safety assessment of new installations, we proposed specific safety requirements associated with co-generation.

To effectively support the licensing of an HTRbased co-generation demonstrator and prototype, work in NC2I-R led to the recommendation that the following activities be conducted in addition to the standard licensing procedure:

- in the pre-application phase, early discussion of the safety features specific for HTR (e.g. passive decay heat removal, use of "vented containment") with the regulator of the host country with the aim to ensure their recognition in the licensing process;

- demonstration that co-generation or process heat application issues are covered by the licensing procedure; - gap analysis for further R\&D needs.

Specific requirements have been outlined which need some more attention for an HTR co-generation application in the areas of:

- safety distances between reactor (possibly reduced Emergency Planning Zone) and heat consuming processes; - radionuclide release limits;

- thermal hydraulic feedback/transients.

\subsection{Deployment scenarios}

In Europe, the economically most attractive near-term opportunities lie in the integration of HTR for powering a large chemical site where process steam is an almost ubiquitous commodity. The integration of a nuclear energy supplier as an Integrated Energy Manager would mean that the number of interfaces on the supplier site of a chemical park would be reduced thus enabling the endusers to concentrate on their core business. 
Following this economic assessment, the next task was to localize and characterize chemical and petrochemical sites in Europe which could represent a potential market for deployment of nuclear cogeneration with HTR. The main processes compatible with HTR capabilities are:

- refinery: steam for fractional distillation;

- petrochemicals: reaction enthalpy;

- industrial sites: steam as commodity;

- paper and pulp: steam for boiling and drying.

Mapping of industrial sites was conducted in a manner allowing to describe the heat market and to characterize industrial sites across Europe. In total, 132 sites were located, 57 of them provided data related to their needs. The majority of sites (20) from where we could collect information use less than $100 \mathrm{MW}_{\mathrm{th}}$. In the category $100-500 \mathrm{MW}_{\text {th }}, 8$ sites were located. There were 9 sites with a heat demand of about $500 \mathrm{MW}_{\text {th }}$ and one above $1000 \mathrm{MW}_{\mathrm{th}}$. The electrical power demand is distributed in a somewhat more uniform manner. The smallest demand - up to $50 \mathrm{MW}_{\mathrm{e}}$ was reported by 20 sites. Each of the next categories, respectively $51-100 \mathrm{MW}_{\mathrm{e}}, 101-200 \mathrm{MW}_{\mathrm{e}}$ and 201-400 $\mathrm{MW}_{\mathrm{e}}$, reported between 4 and 6 sites each.

The analyses performed as part of the NC2I-R project allowed to clearly understand the market, possible deployment sites and the expected energy policy and sustainability impact for near-term steam applications.

\section{The GEMINI + project}

\subsection{Overview}

Based on earlier work in Europe and internationally, the GEMINI+ project (2017-2020) is supporting the demonstration of nuclear cogeneration and is focusing on a particular technology and application of nuclear high temperature cogeneration. GEMINI+ is currently working on a conceptual design for a high temperature nuclear cogeneration system for supply of process steam to industry, a framework for the licensing of such system, and a business plan for a full-scale demonstration.

Among $24 \mathrm{EU}$ partners representing 9 countries one can find 7 research organisation, 2 universities, 2 TSO's, 9 nuclear industries and 3 end-user industries. In the US, the NGNP Industry Alliance (NIA) has a similar objective and approach as NC2I. ${ }^{1}$ In 2014, the twin organisations - NC2I and NIA - decided to join their efforts for demonstration of industrial high temperature nuclear cogeneration and launched the GEMINI initiative meant at coordinating technical development, endeavouring to converge as much as possible in the choice of technologies and design options, as well as actions towards European and US stakeholders for strengthening political support and funding. This GEMINI initiative was soon joined by JAEA (Japan) and KAERI (South Korea) in the GEMINI+ project consortium.

Since about the same time, the Polish government has shown interest to develop HTGR technology for providing heat to its industry. Therefore, this country appears to be

\footnotetext{
${ }^{1}$ www.ngnpalliance.org
}

presently the best candidate for hosting a nuclear cogeneration demonstration in Europe. NC2I therefore decided to focus its efforts on the support of Polish initiatives in this matter. As a first step, NC2I proposed the project GEMINI+ in the frame of the Euratom Framework Programme Horizon 2020 with the objectives of defining:

- the main design options of a demonstration plant addressing the needs of Polish industry;

- a licensing framework adapted to the specific aspects of industrial nuclear cogeneration with modular HTGR systems.

\subsection{Project description}

GEMINI+ is structured in Work Packages.

WP1 is developing a basis for the licensing framework for a modular HTGR

- coupled with industrial process heat applications through a steam network;

- with a safety design fully relying on the intrinsic safety features of modular HTGR.

WP2 is elaborating the main design options of a HTGR system complying with the requirements of WP1 and of end user applications. It is supported by studies on economic optimisation including an assessment of the benefit that can be drawn from the use of modular construction methods presently developed for Small Modular Reactors, on integration into the energy market, and on decommissioning and waste management constraints on the design. Strong interactions between WP1 and WP2 are ensuring the compliance of the design with the safety requirements formulated in WP1.

Though WP2 will essentially select proven design options for getting a demonstration of industrial cogeneration as soon as possible, the project should not miss innovations that appeared in different sectors of technology after the basis of modular HTGR designs been established. It will be checked that integrating such innovations in the design would result in benefits in terms of safety, economic competitiveness and/or flexibility for various end-user applications, without bringing about significant additional risk and delay in the demonstration project. This is the task of WP3, which scrutinizes innovation in different fields (materials, instrumentation, industrial processes, integration in energy networks, etc.) and assess their suitability for the specific GEMINI+ design.

The project is also addressing the conditions of implementation for a demonstration project in Poland. This will be done in WP4 based on a selected industrial site in this country. The siting of the nuclear cogeneration plant and its compliance with the requirements for the considered applications on this site is being assessed. Three other prerequisites are being addressed:

- the availability of a reliable supply chain for the components;

- possibilities to bridge in due time the residual technology gaps that will be identified by the project, in order to be able to guarantee the performance of the system, to justify its safety and to manufacture its components; 

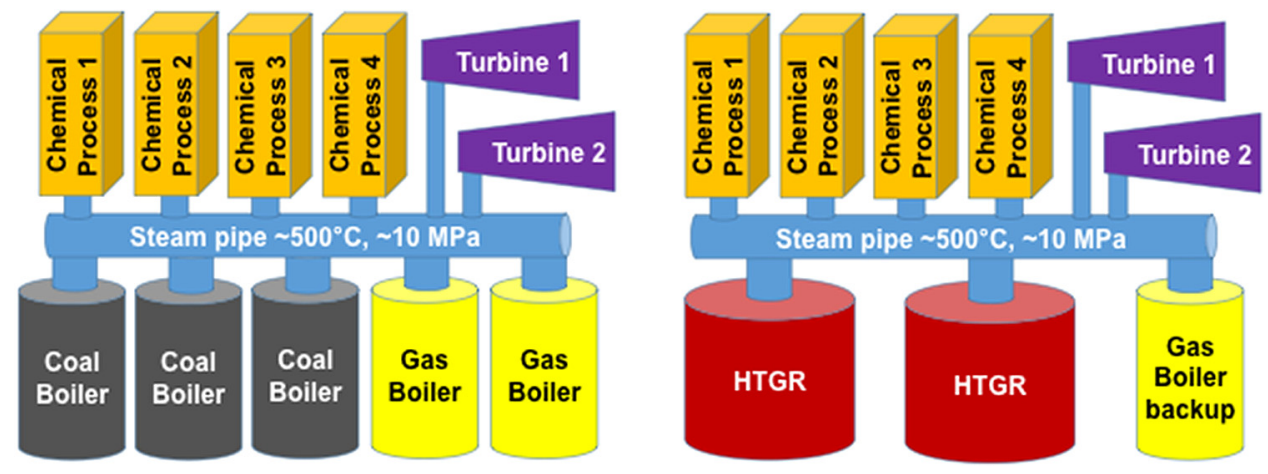

Fig. 4. Replacement of fossil boilers by HTGR.

- a business plan for defining and scheduling the funding needs of the demonstration project and identifying and using funding options.

Finally, WP5 endeavours to provide a favourable environment to the demonstration project by

- further developing the international partnership;

- soliciting advice and support from industry via a Business Advisory Group;

- supporting competence building of a Polish team on HTGR technology;

- creating a knowledge management basis and repository for all available documentation on HTGR technology, in particular the documentation created or recovered in the frame of previous European projects.

\subsection{System requirements}

In Poland, system requirements have been consolidated through a Polish national project "HTR-PL" and through the work of an official Polish HTR Committee gathering industry (end users and engineering companies), nuclear research and funding organisations, appointed by the Ministry of Energy. This Committee published in 2017 its final report with an assessment of the potential for deployment of HTGR industrial cogeneration in Poland [9] and a synthesis of Polish end-user needs. The common denominator of the Polish industrial needs is the following:

- Energy should be supplied only in the form of superheated steam delivered to existing steam networks presently fed by fossil fuel fired boilers. If the site requires electricity supply, it is already generated on most of the cases by existing turbo-generators connected to the steam network, and this organisation should not be disturbed by the substitution of conventional boilers by nuclear plants (Fig. 4).

- The steam networks are fed with steam at $540{ }^{\circ} \mathrm{C}$, 13.8 MPa.

- The common denominator of the steam needs of the Polish sites is $230 \mathrm{t} / \mathrm{h}$, which corresponds to a power delivered to the end-users of $165 \mathrm{MW}_{\mathrm{th}}$.

On the other hand, industry is expecting the cost of the steam delivered by the nuclear plant to be attractive, i.e. not higher than the cost of steam delivered by fossil fuelfired boilers.

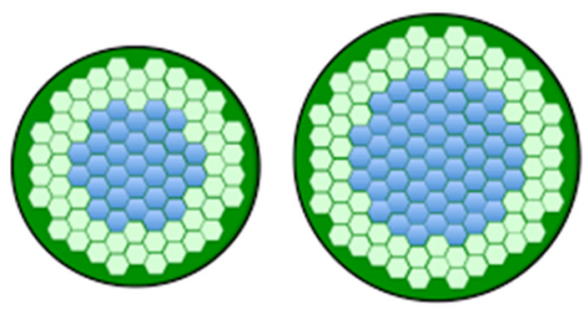

Fig. 5. HTGR core.

\subsection{Conceptual design of the reactor}

The first design option is a block type core because NC2I, NIA, JAEA and KAERI have experience with this type of design: TRISO coated particles are embedded, mixed with matrix graphite and pressed to small cylinders, the "compacts"; these are stacked into vertical channels of prismatic graphite blocks that in turn are piled up to form the core. The heat is removed by helium gas blowing through additional vertical cooling channels across these blocks. GEMINI+ uses the same compact and block design as the $625 \mathrm{MW}_{\text {th }}$ SC-HTGR developed by Framatome Inc.

The design power of the GEMINI + reactor will be reduced from the SC-HTGR power to meet the requirements of the Polish and most other European end users, as it appeared in a survey performed by the project NC2IR. For the lower power selected for the Polish industry, the core will be cylindrical and not annular like the SCHTGR core, which makes it more compact and minimizes the dimensions of the reactor pressure vessel in order to make the fully assembled vessel transportable. Two possible core configurations, presented in Figure 5 are considered, and are being assessed in terms of vessel lifetime (acceptable integrated fast neutron fluence), maximum fuel temperature in accident conditions, feasibility of reactivity control and transportability of the vessel.

A sufficient number of barriers between the nuclear fuel and the non-nuclear steam network is required to exclude radio-contamination of the steam product. Therefore, the process steam for the end user is not produced in a steam generator interfacing with the primary circuit, but instead, a secondary circuit is employed. Different heat transfer fluid options have been examined and steam was selected as 


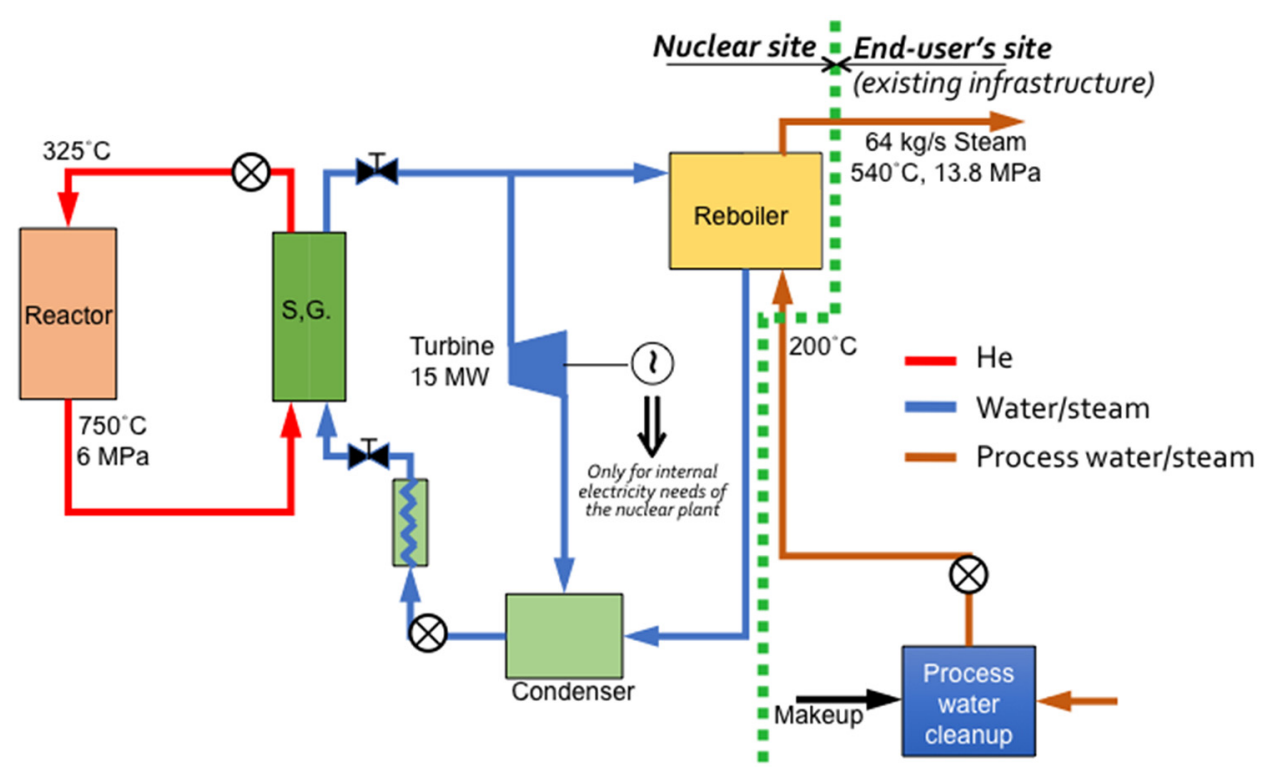

Fig. 6. General configuration of the nuclear plant with $185 \mathrm{MW}_{\text {th }} \mathrm{HTR}$.

the best proven technology. It is produced in a steam generator and then condensed in a reboiler, at the interface with the industrial steam network (Fig. 6).

Even if the modular HTGR does not require electric power supply to be kept in safe conditions, keeping the reactor available to supply steam to the steam network requires continuing reactor operation even in case of loss of external power supply. A small turbo-generator located in the secondary circuit will therefore generate the power required for the house load of the nuclear plant, and the thermal power required to produce the steam branched off to the internal turbine is estimated to be about 15-20 $\mathrm{MW}_{\mathrm{th}}$. The thermal power of the reactor should therefore be $180-185 \mathrm{MW}_{\mathrm{th}}$.

\section{Conclusion}

HTR technology has been recognised by several countries and international organisations as the most promising technology to provide heat for industrial processes, including hydrogen production. The projects "NC2I-R" and "Gemini+" prepare the way for practical deployment of this technology. Now is the time to begin the reactor design and prepare the site for the first construction. Several companies in Poland are interested and they have got a green light from the minister of energy to initiate the project. The first commercial HTR is expected to produce energy by 2030-2032, while by 2050 High Temperature Reactors should be used widely.

\section{References}

1. International Energy Agency, World Energy Outlook 2018, www.iea.org/weo.

2. All data for energy in EU28 for 2015: http://ec.europa.eu/ eurostat and http://heatroadmap.eu/

3. A. Bredimas, Market study on energy usage in European heat intensive industries, EUROPAIRS project, FP7, Deliverable $131,27 / 05 / 2011$

4. A. Bredimas, Results of a European industrial heat market analysis as a pre-requisite to evaluating the HTR market in Europe and elsewhere, Nucl. Eng Des. 271, 41 (2014)

5. Advances in Nuclear Power Process Heat Applications IAEA-TECDOC-1682, 2012

6. NC2I Vision Paper, June 2018, www.nc2i.eu

7. The Sustainable Nuclear Energy Technology Platform. A vision report, 2007, www.snetp.eu

8. C. Angulo et al., EUROPAIRS: The European Project on Coupling of High Temperature Reactors with Industrial Processes, Nucl. Eng. Des. 251, 30 (2012)

9. Possibilities for deployment of high-temperature nuclear reactors in Poland, Ministry of Energy, Warsaw, 2017. www.tiny.cc/htr-pl

Cite this article as: Grzegorz Wrochna, Michael Fütterer, Dominique Hittner, Nuclear cogeneration with high temperature reactors, EPJ Nuclear Sci. Technol. 6, 31 (2020) 